\title{
Green Development Research in Steel Industry
}

\author{
Yan $\mathrm{Yu}^{1, a}$ \\ University of Science and Technology LiaoNing, China \\ asyuyan@126.com
}

\begin{abstract}
Keywords: iron and steel industry, low-carbon technology, emissions reduction of carbon dioxide Abstract. Iron and steel industry, as the important foundation of the national economy, has been developed rapidly in recent years. However, with constant expansion of steel production, industrial emissions and pollution problem is increasingly outstanding, the previous extensive development mode cannot adapt to the modern iron and steel industry demand. How to reduce the emission pollution, energy consumption, and develop the green steel economy, have become the important subjects that iron and steel enterprises are facing.
\end{abstract}

\section{Introduction}

Since the mid - 1990 - s, iron and steel enterprises developed gradually into the era of more integrated green production, the purpose of energy conservation and environmental protection work is no longer simply through the environmental protection measures to reduce pollutants discharge, or the new technology to reduce energy consumption, instead the enterprise efficiency and competitiveness, protect the environment, save energy resources and reduce greenhouse gas emissions as a whole to consider.

\section{The latest technology of the Green steel industry development abroad and the present situation analysis}

At present, many developed countries and regions take different approaches and technology strategies for $\mathrm{CO} 2$ emission reduction. The United States, Japan, Korea, Australia and Canada active participate in the Asia-Pacific on clean development and climate partnership, China and India are also involved in the project. The EU has established the mechanism of international trade of the world's biggest greenhouse gas emissions. Main driving force to promote the development of energy conservation and environmental protection technology in developed countries has the following three aspects:

Product technology and quality At present,The iron and steel industries in many developed countries are using research and development of environmentally friendly production techniques and breakthrough of smelting process. For example, the European steel enterprises make full use of local as the iron and steel production and research and development base, increase the use of energy-saving products and energy-saving technology, at the same time, keep close relations with the EU manufacturers. The goal is to take various actions to deal with global warming, at the same time for Europe to contribute to the economic growth and increase employment. According to EU greenhouse gas emission reduction targets clear, strength reduction is bigger, and their own scrap the characteristic of the large capacity, so make increase the proportion of scrap steel, reduce the demand for hot metal as the most effective measures to reduce the $\mathrm{CO} 2$ emissions.

Equipment and production technology Since the $60 \mathrm{~s}$ and $70 \mathrm{~s}$ last century, the United States electric furnace steel production increased dramatically, in recent years the proportion of electric steel has more than $60 \%$, electric furnace steel making has become the main steel making process in the United States. Electric steel developed rapidly in the United States and more than the dominant reason of converter steel, the first is the United States has plenty of cheap scrap steel, electric power resources; Second enterprises' low investment, short construction period, the production and business operation flexibility, another important factor is the furnace short flow process in the aspect of energy conservation and environmental protection is much stronger than the converter process technology consume with a large amount of coke, high carbon emissions . In view of the steel industry, The U.S. 
department of energy has developed the following technologies by the form of international cooperation: no coke iron making technology, with rotary hearth furnace DRI production or grain of iron as a supplementary materials such as electric furnace; LCS laser linear measuring system such as refractory brick thickness measurement of converter and ladle, extend equipment life, save the energy consumption of refractory material; High strength roll; DOC system, through a separate high-speed nozzle jet fuel gas and oxygen, make the heating before mixing gas and oxygen, can improve the yield and efficiency of rolling mill; Galvanized zinc waste removal techniques.

Efforts to create all the resources recycling society The Japanese steel industry serious on energy conservation, by making full use of surplus energy and efficient utilization of recovery waste gas, improve energy efficiency; Have been trying to reduce the industrial waste landfill and contribute to creat a better society in many other ways, such as using new steel scrap steel production, etc. In addition, iron and steel enterprises use the by-product of the iron and steel production process, such as slag, furnace and furnace dust mud used as a new resource, also the use of waste plastics, waste tires and other recycled materials. Japan iron and steel industry has established a goal, that is, before the year 2020 will reduce landfill waste to 500000 tons, equivalent to less than $75 \%$ of the 1990 , and the steel tank recovery rate increased to $85 \%$.

\section{Green development present situation and existing problems of iron and steel industry in China}

Current situation of the development of In 1981, China's crude steel production is about a third in the United States, by 1996, China's crude steel output reached 100 million tons, leaps to the world. By 2015, China's crude steel out put of 800 million tons, accounting for $49.53 \%$ of the global total, than the next eight countries combined. Titles, 20 years is worthy of the name steel superpower. But the traditional iron and steel industry is high energy consumption, high water consumption, high pollution industry. Over the past five years, China's iron and steel industry energy conservation and emissions reduction got greater achievements, comprehensive energy consumption of per ton steel and energy consumption of declining in each process. In 2011, the steel industry through technical innovation, backward, new progress has been made in energy conservation and emissions reduction, many large and medium-sized enterprises generally improved technical and economic indicators in various production processes, comprehensive energy consumption of per ton steel $601.72 \mathrm{~kg}$ of standard coal/ton, new water consumption of per ton steel 3.88 cubic meters, COD discharge 26700 tons. In 2015, the total energy consumption in iron and steel industry in China fell for the first time in nearly 30 years. The steel industry comprehensive energy consumption of per ton steel has been reduced to $580 \mathrm{kilograms}$ of standard coal/ton or less. Energy consumption reduction is not only attributed to pure steel production is falling,but also the energy conservation and emissions reduction technology to lower the comprehensive energy consumption of per ton steel. As the total decline of comprehensive energy consumption of per ton steel and energy consumption,all kinds of pollutant emissions have fallen dramatically. "twelfth five-year" plan to develop the new water consumption of per ton steel is 4 tons, and in 2015 dropped to 3.26 metric tons of iron and steel industry in our country. At present, most of the iron and steel enterprise sintering machine on the desulfurization facilities, sulfur dioxide emissions has been reduced to $0.88 \mathrm{~kg} /$ tonne of steel, and the goal of "twelfth five-year" plan is dropped to less than $1 \mathrm{~kg} / \mathrm{ton}$. Although the steel industry has obtained the very big progress in energy conservation and environmental protection, but on the processing of certain pollutants still a gap with the international advanced enterprises.

\section{Existing problems}

- The quality of steel products

At present, the main problems existing in varieties of quality of the iron and steel industry is unreasonable varieties structure, low quality class. According to metallurgical industry survey statistics, at present only a few domestic enterprises product can compete on foreign big companies' quality, and most companies products is low, low output and quality can not meet the users demand, each year we need imported a large number of steel products from abroad in China. And some of the existing alternative steel grade, the quality of the products and also exists certain gaps when compared with abroad, such as low purity and impurity content is higher, the performance was lacking. 
-The process equipment

In recent years, equipped with large-scale iron and steel enterprises in China have made great progress, the new large blast furnace adopts a series of advanced technology and equipment, many is based on the domestic independent development, technology integration, innovation and development results. But the low proportion of our electric furnace steel production, steel scrap utilization degree is low. At present most of the United States, South Korea and other developed countries given priority to the steel industry short flow , the output of electric steel are more than $50 \%$ of the total steel production, in 2009 , the proportion of electric furnace steel production in China accounts for only about $10 \%$.

-Technology and equipment level

Overall, there is a lack of China's iron and steel enterprises in the process, technology, production processes and environmental protection technology, some advanced energy saving technology and equipment are used less. Even the abroad application of common energy-saving technology - dry quenching technology of coking, iron and steel enterprises in China are only a few large companies such as Bao Steel, Jinan and Shou Steel introduced to use the technology. According to the statistic department of metallurgical industry, backward technology and equipment in our country is still quite a share, only $10 \%-20 \%$ of total domestic production of equipment can enter the international advanced level, has been the implementation of high efficiency continuous casting casting machine accounts for only $10 \%$ of the total, a fair amount of ordinary steel production capacity to phase out or modification, and the key to national economy need varieties can only meet the needs of about two-thirds

- Iron and steel industry concentration degree is low

It is necessary to solve the problem about Low industrial concentration for the development and industrial structure adjustment of steel industry in China , also caused our country iron and steel industry is one of the main reasons for high carbon dioxide emissions. Because of the low industrial concentration, which leads to the unreasonable resource allocation,low competition ability, high energy consumption per unit of production and material consumption, companies continue to expand production scale, caused serious pollution of the environment and market chaos, exacerbated by low-level redundant construction.

\section{China's iron and steel industry development trend of green}

The China iron and steel association, attaches great importance to the green development of the industry, has also done a lot of work in energy conservation and environmental protection. One is in each of the five year plan, organize experts steel industry energy conservation and emissions reduction, clean production, the key technology of circular economy; The second is to guide 、 organize and conduct business major energy conservation and emissions reduction, comprehensive utilization of resources of technology research and development cooperation; Three is to organize the energy conservation and environmental protection in the industry for the activity; Four is to organize screening, the promotion of energy conservation, environmental protection and clean production of advanced technology; Five is the iron and steel industry energy conservation and environmental protection conduct of the typical demonstration activities; Six is working with machine and metallurgy building materials trade unions hold large blast furnace, converter, such as large energy consumption on the activities of energy efficiency of the equipment.

Establish distinctive innovation system of iron and steel industry Industrial innovation system based on market demand for power, guided by policy regulation, by the good environment for security both at home and abroad, in order to supply innovative technology as the core, in order to realize the specific industrial innovation as the goal of network system. We should pay attention to improve the iron and steel industry policy system construction, conducive to innovation, perfect for iron and steel technology system and evaluation system of industrial innovation, eventually establish the iron and steel industry innovation system with distinctive features, in the service of "green steel" development, design, manufacturing process, etc

The development of green high iron and steel products In recent years the iron and steel enterprises and practical environmental protection technology and equipment constantly updated, the 
iron and steel enterprises of the pollutants emissions dropped year by year, but in some part of the iron and steel production is still lack of applicable techniques. In this case, the development of efficient environmental protection products become a trend. In the future a long period of time, compared with other materials, iron and steel materials in both its performance and recycling, etc., still have irreplaceable advantages, iron and steel products is still a social development choice and optimization of material. Circular economy society need to provide more "green" steel iron and steel enterprise, is to realize the function of the material with minimal cost. On the premise of meet the material function, through clean production, longevity, efficient social environment load steel products.

Increase the recycling technology and management level China's many iron and steel enterprises, especially small and medium-sized steel enterprises more than waste heat pressure and other underutilized, waste heat resource recovery rate of only $25.8 \%$, down nearly $20 \%$ compared with abroad. So we must adopt new technology as far as possible to develop recycling. Must strengthen the tally maintenance and orientation management at the same time, increase operation rate, to maintain and improve the recovery rate.

Set up industrial cluster, and expand the value of iron and steel process As a typical process industry, process function diversity, the characteristics of the target diversity, value diversity, iron and steel enterprise should fully explore the iron and steel process advantages in equipment, process, technology, management, technology development on energy conversion, the given and recycling of waste disposal, improve enterprise comprehensive value, make the iron and steel enterprises into the circular economy society. Make the industrial ecology theory, the development of material, energy, water ecological industrial chain, build the iron and steel enterprises as the core, to form a symbiotic industrial clusters that, to make optimal use of matter and energy in a region.

\section{Conclusions}

Chinese steel industry will be guided by the market demand, focus on the structure adjustment, center on the economic benefits, be driven by technological advances, transfer the mode of growth and set up scientific and technological innovation system, speed up independent innovation ability and international competitiveness, and improve the quality and efficiency of iron and steel industry; Adjust the composition of steel varieties, improve the domestic steel market share; strengthen environmental protection, reduce pollution, and keep the coordinated development with environment.

\section{Acknowledgment}

First and foremost, I would like to show my deepest gratitude to Professor X.J. LU. Conversations with him have been most helpful. I shall extend my thanks to Mr. Ao for all his kindness and help. This work has been supported by The Applied school of University of Science and Technology Liaoning.

\section{References}

[1] Xianyang Xu, China Radio and TV Press, 2002. In Chinese.

[2] ShouLan Yu; Shaohua Wu, China Machine Press, 2003. In Chinese.

[3] JiaJu Zhang, China's steel magazine, 1998(1). In Chinese. 